\title{
MANAGEMENT AND BIOSECURITY PRACTICES ON BROILER AND LAYER FARMS IN BAHRI LOCALITY KHARTOUM NORTH
}

\author{
Omer, A., Salim Gibril and Abdelbasit B. Habib*
}

Department of Poultry production, College of Animal Production, University of Bahri, Sudan.

* Corresponding author: Abdelbasit B. Habib; email; abdelbasitbasheer@yahoo.com

\begin{abstract}
This study was conducted to evaluate the present status of management and biosecurity practices in broiler and layer farms in Khartoum North, Sudan, and to compare between the biosecurity practices in broiler and layer farms. The primary information included farm characteristics, technical management practices and biosecurity practices carried out in each of these farms. A total of 30 farms (20 broilers and 10 layers) were chosen from Khartoum North .The data were collected using structured questionnaire. The respondents were farm owners, farm managers, and veterinarians. The results showed that the broiler farms had a higher level of biosecurity than the layer farms. The average mortality of the broiler house was $5.5 \%$ when compared with $6.45 \%$ of the layer, type of bedding material $100 \%$ for broiler compering with $70 \%$ for layer, close system in the farm visited are $60 \%$ and $30 \%$ in broiler and layer the biosecurity levels were regarded as high in the chicken meat sector but no assessment was made on the chicken egg sector due to a low response rate and high level of rodent and insect control. In addition, the results indicated that broiler and layer farms do not allow for visitors to enter of about $60 \%$ and $40 \%$ respectively. Only $10 \%$ of visitors change their cloths for layer farms compared with $45 \%$ for broiler farms, while $60 \%$ and $40 \%$ have no animal restriction policy
\end{abstract}

Original Article:

https://dx.doi.org/10.21608/j avs.2019.62651

Received 03 July 2019.

Accepted 22 July 2019.

Published in October 2019.

This is an open access article under the term of the Creative Commons Attribution 4.0 (CC-BY) International License . To view a copy of this license, visit http://creativecommons.org/lic enses/by/4.0/

J. Appl. Vet. Sci., 4(2): 30-34.

Keywords: Bahri, biosecurity, broiler, Farm characteristics, layers.

\section{INTRODUCTION}

The goal of the poultry industry is to provide an economical, safe and sustainable meat source for consumers while maintaining a profitable market. With this goal, disease prevention on the commercial poultry farms is an essential component to providing such a product (English, 2015). There is a continuous loss due to diseases which should be reduced through strict biosecurity programme. Changing legislation and consumer acceptance and preference on the allowable levels of certain pathogens in poultry products has encouraged the industry to examine biosecurity practices at farm level more closely (Singer, 2006).

Biosecurity is defined as "the protection of agricultural animals from invading infections, in other words, Biosecurity is the implementation of measures that reduce the risk of introduction and spread of disease agents. In the poultry industry it includes practices such as footbath use, disposable shoe covers worn inside houses and restricting farm access to necessary personnel (Biosecurity procedures in poultry production, 2018). English, (2015) conducted two surveys to study farm characteristics, management characteristics and biosecurity practices in some poultry farms in the USA and reported variations in these parameters between the farms studied. In the Sudan, there is no common biosecurity program applicable to all poultry production farms (Tabidi, et al., 2014). Few studies Ali, et al, (2014), Mustafa and Ismail, (2017) were conducted to evaluate biosecurity measures in both layers and broilers farms respectively in Khartoum State.

Despite this, many parameters such as house and farm characteristics as well as other management practices that should have been taken into consideration when implementing a biosecurity program were not properly addressed. Investigation of such parameters as well as the examination of the compliance of individual farms with the actual biosecurity practices as cited in the regulations is very important in the Sudan. 
The purpose of this study therefore was to collect data via a survey on all farm characteristics, management and biosecurity practices performed in bahri locality to check the biosecurity measures adopted in these farms with the intent of identifying strengths and weaknesses in their biosecurity program

\section{MATERIALS AND METHODS}

\section{Area of the study}

This study was carried out in the three provinces of North Bahri namely Alkadaro, Eastern Nile and Halfaya during the period from 25 August 2018 to 2 November 2018.

\section{Data Collection}

Practical field survey had been conducted with special designed questionnaire to collect data for the study. Information collected included farm characteristics (number of houses on the farm, house dimension, age of houses, number of birds on the farm, number of flock per year, percent mortality in current flock) technical management practices (bedding material, how often litter was removed, how litter was disposed and biosecurity practices (rodent control program, insect control program, farm visitors limited, foot baths, soap and water/ sanitizer available shower in/out, visitors change clothing before entry, other animal restriction). A number of 20 and 10 broiler and layer farms respectively were identified and their managers and veterinarians were asked to fill the structured questionnaire by the direct contact of the author.

\section{Statistical analysis}

All questionnaires were assembled and the information and data collected were tabulated and statistically analyzed using statistical package of social sciences (SPSS) computer program (version 12) according to Quintero, Dino; et al (2012).

\section{RESULTS}

The following tables show the obtained results on broilers and layers house characteristics including flock number, mortality, type of housing, fencing characteristics, management characteristics, rodent and insect control, biosecurity practices, farm visitor and use of soap and water, biosecurity practices and animal restricted biosecurity practices in bahri Khartoum North. The study investigated farm characteristics which are very important to provide information about the history of the farm. In addition, it can assist very much in the evaluation and interpretation of any future outcomes.
Table 1. Broilers and Layers house characteristics in Bahri, Khartoum North

\begin{tabular}{|l|l|l|}
\hline \multirow{2}{*}{ Parameters } & \multicolumn{2}{|l|}{ No. of houses on farm } \\
\cline { 2 - 3 } & $(20)$ Broilers & $(10)$ Layers \\
\hline Average & 3.75 & 2.9 \\
\hline Minimum & 1.0 & 1.0 \\
\hline Maximum & 8.0 & 10.0 \\
\hline $\begin{array}{l}\text { Dimension of } \\
\text { the house (m2) }\end{array}$ & $(20)$ broiler & $(10)$ layers \\
\hline Average & 170.6 & 695.2 \\
\hline Minimum & $70 \times 12$ & $24 \times 8$ \\
\hline Maximum & $115 \times 13$ & $100 \times 15$ \\
\hline $\begin{array}{l}\text { Age of house } \\
\text { (year) }\end{array}$ & $(20)$ broilers & $(10)$ layers \\
\hline Average & 11.95 & 18.0 \\
\hline Minimum & 1.0 & 3.0 \\
\hline Maximum & 39.0 & 65.0 \\
\hline
\end{tabular}

Table 2. Broilers and Layers flock number and mortality characteristics in Bahri, Khartoum North

\begin{tabular}{|l|l|l|}
\hline \multirow{2}{*}{ Parameters } & \multicolumn{2}{|l|}{ Number of flocks per year } \\
\cline { 2 - 3 } & 20 broiler & 10 layers \\
\hline Average & 3 & 1.25 \\
\hline Minimum & 4 & 1 \\
\hline Maximum & 6 & 2 \\
\hline $\begin{array}{l}\text { \% of mortality } \\
\text { in current flock }\end{array}$ & $(20)$ broiler & $(10)$ layers \\
\hline Average & $5.5 \%$ & $6.45 \%$ \\
\hline Minimum & $2.5 \%$ & $0.7 \%$ \\
\hline Maximum & $10 \%$ & $15 \%$ \\
\hline
\end{tabular}

Table 3. Broilers and Layers housing and fencing characteristics in Bahri, Khartoum North.

\begin{tabular}{|l|l|l|}
\hline Parameters & \multirow{2}{*}{$(20)$ broilers } & $(10)$ layers \\
\hline Type of housing & $12(60 \%)$ & $30 \%$ \\
\hline Close & $3(15 \%)$ & $40 \%$ \\
\hline Semi-close & $5(25 \%)$ & $30 \%$ \\
\hline Open & $(20)$ broilers & $(10)$ layers \\
\hline $\begin{array}{l}\text { Type of broad } \\
\text { fencing used }\end{array}$ & $12(60 \%)$ & $60 \%$ \\
\hline Barbed wire & $4(20 \%)$ & - \\
\hline Zink & $2(10 \%)$ & $30 \%$ \\
\hline Wall & $2(10 \%)$ & $10 \%$ \\
\hline Open (no walls) & & \\
\hline
\end{tabular}


Table 4. Broiler and layer management characteristics in Bahri locality, Khartoum North

\begin{tabular}{|l|c|c|}
\hline $\begin{array}{l}\text { Type of bedding } \\
\text { material }\end{array}$ & (20) Broilers & (10) Layers \\
\hline Sawdust & $80 \%$ & $50 \%$ \\
\hline Concrete & $20 \%$ & $20 \%$ \\
\hline $\begin{array}{l}\text { How litter is } \\
\text { remover }\end{array}$ & (20) broilers & (10) layers \\
\hline $\begin{array}{l}\text { Completely } \\
\text { removed }\end{array}$ & $90 \%$ & $100 \%$ \\
\hline Flipping & $10 \%$ & 0 \\
\hline $\begin{array}{l}\text { How Litter of } \\
\text { disposed }\end{array}$ & (20) Broilers & (10) layers \\
\hline Sale & $65 \%$ & $100 \%$ \\
\hline Burn and Sale & $10 \%$ & 0 \\
\hline Burial and burn & $25 \%$ & 0 \\
\hline
\end{tabular}

Table 5. Broiler and layer rodent and insect control in biosecurity practices in Bahri, Khartoum north

\begin{tabular}{|l|l|l|}
\hline Parameters & (20) Broiler & (10) Layers \\
\cline { 1 - 1 } $\begin{array}{l}\text { Rodent control } \\
\text { program }\end{array}$ & $25 \%$ & $20 \%$ \\
\hline No fight & $20 \%$ & $20 \%$ \\
\hline Counter strike & $20 \%$ & $60 \%$ \\
\hline $\begin{array}{l}\text { Specialize } \\
\text { companies }\end{array}$ & $15 \%$ & 0 \\
\hline Poisons & $40 \%$ & $(10)$ layers \\
\hline Insect control & $(20)$ broilers & $40 \%$ \\
\hline $\begin{array}{l}\text { Pesticides } \\
\text { Periodic fire }\end{array}$ & $10 \%$ & $30 \%$ \\
\hline No insect & $25 \%$ & \\
\hline
\end{tabular}

Table 6. Broilers and Layers farms visitor and use soap and water biosecurity practices in Bahri, Khartoum North

\begin{tabular}{|l|c|c|}
\hline Parameters & (20) broilers & (10) layers \\
\cline { 1 - 2 } Farm visitor limited & $30 \%$ & $30 \%$ \\
\hline Specific condition & $60 \%$ & $40 \%$ \\
\hline Not allowed & $10 \%$ & $30 \%$ \\
\hline Allow water & $(20)$ broilers & $(10)$ layers \\
\hline $\begin{array}{l}\text { Soap \& } \\
\text { available }\end{array}$ & $25 \%$ & $40 \%$ \\
\hline Available & $25 \%$ & $10 \%$ \\
\hline Sometime & $50 \%$ & $50 \%$ \\
\hline No & $45 \%$ & $10 \%$ \\
\hline Visitors change cloth & $(20)$ broilers & $(10)$ layers \\
\hline Yes & $30 \%$ & $90 \%$ \\
\hline No & $25 \%$ & - \\
\hline Sometime & $(20)$ broilers & $(10)$ layers \\
\hline Footbath & $75 \%$ & $80 \%$ \\
\hline Yes & $25 \%$ & $20 \%$ \\
\hline No & & \\
\hline
\end{tabular}

Table 7. Broilers and layers Animal restricted biosecurity practices in Bahri, Khartoum North

\begin{tabular}{|l|l|l|}
\hline Parameters & \multirow{2}{*}{ (20) broilers } & (10) layers \\
\cline { 1 - 2 } Other animal restricted & $15 \%$ & $20 \%$ \\
\hline Goat & $15 \%$ & $30 \%$ \\
\hline Cow & $15 \%$ & $0 \%$ \\
\hline Indigenous chicks & $5 \%$ & $40 \%$ \\
\hline Nothing & $60 \%$ & \\
\hline
\end{tabular}

\section{DISCUSSION}

The broiler and layer house characteristics in bahri, Khartoum north are shown in table (1). The table indicates the minimum, average and maximum numbers of houses within the farm, dimension of the house, age of house in 20 and 10 broiler and layer farms respectively obtained from 3 localities in bahri area. The average number of houses in the farm visited was 3.75 and 2.9 for broiler and layer house respectively. The figures obtained indicated that broiler farms are more than that of layers. This result is similar to that obtained by Tabidi, et al (2014) who reported that the percent of broiler farms $(69.5 \%)$ was found to be greater than that of layer farms $(30.5 \%)$ at Khartoum Bahri provinces. In addition, the table also shows that the average dimensions of the house in the farm are 170.6 and $695.2(\mathrm{~m} 2)$ for broiler and layer house respectively while maximum $115 \times 13$ and $100 \times 15(\mathrm{~m} 2)$ and minimum $70 \times 12$ and $24 \times 8(\mathrm{~m} 2)$ houses were seen in broiler and layer farms respectively.

These results indicated that most broiler and layer farms are using the correct dimensions as recommended. Moreover table (1) also shows that the average age of the house was 11.95and 18(year), the minimum 1and 3(year) and the maximum 39 and 65 (year) for broiler and layer houses respectively. The figures obtained indicated that broiler farms are less old than that of layers. This result reveals that farmers in this locality adopted layer production before broiler production.

Broilers and Layers flock number and mortality characteristics in Bahri, Khartoum North are indicated in table (2). The table shows the characteristics of the farm, minimum average and maximum number of flocks per a year and percent mortality in current flock in 20 and 10 Broiler and layer farms. Flock number and mortality are very important parameters that infers about the bird's accommodation and the health status of the flock. Moreover, bird mortality must be recorded on a regular basis to assist monitoring for any unusual animal health problems potentially indicating a 


\section{Omer A, Salim Gibril And Abdelbasit B. Habib}

biosecurity breach. In addition, table (2) also shows that the average mortality of the house in the farm is $5.5 \%$ and $6.45 \%$ for broiler and layer houses respectively. The figures obtained indicated that broiler farms are better than that of layers in terms of mortality. These figures are within the range of mortality suggested by Smith and Daniel, (1975). The present results are higher than that obtained by English, 2015 who reported $(1.75 \%)$ and $(2.2 \%)$ mortalities for broiler and layer farms. This difference in mortality can be attributed to difference in mortalities.

Broilers and Layers type of housing and fencing characteristics in Bahri, Khartoum North, are indicated in table (3). The table shows the type of housing in 20 and 10 broiler and layer farms respectively. The adoption of close system in the farms visited is $60 \%$ and $30 \%$ in broiler and layer houses respectively. The figures obtained indicated that most broiler farms are owned by giant industries that have the financial ability to adopt this system. In addition, the table also shows that the type of fencing used is, barbed wire in $60 \%$ of both categories, wall in $10 \%$ and $30 \%$, and open (no walls) in $10 \%$ of both. On the other hand, Zink was used in only $20 \%$ of broilers farms. The figures obtained suggest that barbed wire is the most suitable type of fencing in the area. This result agrees to that of English, (2015) who reported that the majority of farms use metal brood fencing, followed by plastic, both or other. However, no results for the type of fencing used carried in the Sudan for comparison.

The broiler and layer farms management characteristics in Bahri locality, Khartoum North are shown in table (4). The table indicates the type of bedding material, how litter is removed, how litter is disposed of in 20 and 10 broiler and layer farms respectively obtained from 3 localities in bahri area. The use of sawdust in the farm visited constitute about $80 \%$ and $50 \%$ for broiler and layer respectively, which indicates that sawdust is the most preferable bedding material in the area. This result contradicts that obtained by English, 2015 in USA who reported that, the majority of growers use pine shavings as the bedding materials. Moreover, table (4) also shows that litter is disposed through sale in $65 \%$ and $100 \%$ in broiler and layers farms respectively and $10 \%$ and $25 \%$ through burn and sale and burial and burn respectively in broiler farms only. Based on the results of this table it is clear that most litter is disposed of through sale. This result is justifiable on the ground that poultry litter is normally purchased to be used as natural fertilizer in agricultural lands. This result is different to that obtained by Negro et al (2013) who reported that the percent of sale litter was $1.7 \%$. The difference in results can be attributed to country and the type of use.
The broiler and layer biosecurity practices in bahri, Khartoum north are shown in the table (5) The table indicates the rodent control program and insect control within the farm, in 20 and 10 broiler and layer farms respectively obtained from 3 localities in bahri area. The table shows that $20 \%$ and $10 \%$ of broilers and layer farms respectively have rodent control programme, while $25 \%$ and $20 \%$ have no programme of fight. However, counter strike control was $20 \%$ in both. In addition, $15 \%$ and $60 \%$ of farms respectively make contract with specialized companies while $40 \%$ of broilers farms use poisons for rodent control. These results show that rodent and insect control are better practiced in layer farms than broiler farms due to the long production period in layer farms that necessitate the adherence to these types of biosecurity programs.

The broiler and layer biosecurity practices in bahri, Khartoum north are shown in table (6) The table indicates the farm visitor limited, soap and water availability, visitor change cloth and footbath.The table shows that both of the farm categories allow 30\% visitors under specific conditions, $10 \%$ and $30 \%$ of the farms respectively do not allow visitors. Clothing changed before entering or exiting farm. In addition, the table also shows soap and water are found available in $25 \%$ and $40 \%$ in broiler and layer farms respectively. On the other hand, soap and water are not available in $50 \%$ of both. The table also shows that visitors change cloth in $45 \%$ and $10 \%$ broiler and layer farms respectively, and don't change cloth in $30 \%$ and $90 \%$ respectively.

Moreover table (6) also shows that the footbath is found in $75 \%$ and $80 \%$ of broiler and layer farms respectively, however, $25 \%$ and $20 \%$ of them don't use footbath. Results of table 6 clearly indicated that broiler farms are stricter in biosecurity measures as regard visitors than layer farms and both of farm categories are not very strict in soap availability and layer farms showed better adoption to changing of visitor's cloths and use of footbath. These results are not in accordance with other results obtained in different countries (Scott, et al 2018; Yitbarek et al 2016; and Ajewple, et al 2014). The differences between the results of the present study the early literature mentioned can be attributed to different legislations and housing conditions in the places where these studies were carried out.

The broiler and layer animal restricted biosecurity practices in bahri, Khartoum north are shown in table (7). The table indicates the animal restricted biosecurity program in the farm visited. Goats and cows are the most restricted animals with $15 \%$ and $20 \%$ in broiler and layer farms respectively for the former and $15 \%$ and $30 \%$ for the latter and with 
only $5 \%$ for indigenous chickens in broiler farms while $60 \%$ and $40 \%$ have no animal restriction policy. These results clearly demonstrate that animal restricted biosecurity measures are less adopted in broiler farms due to the fact that most broiler farms are of modern accommodations that prevent the entrance of such animals. These results are similar to the results of other studies conducted in the Sudan (Tabidi, et al 2014; Mustafa and Ismail, (2017) and Ali, et al, 2014.

\section{CONCLUSION}

The study results highlighted the biosecurity practices in Bahri, Khartoum North. Clear evidences of weakness were observed in percent mortality and visitor change cloth in layer farms, while evidences of strength were seen in rodent and insect control and completely removed of bedding material at the end of each period.

\section{ACKNOWLEDGMENT}

The authors would like to thanks the owners of broiler and layer farms in the study area for their cooperation.

\section{Declaration of Competing interest}

On behalf of all authors, I hereby declare that no conflict of interest may interfere with the publication of the manuscript.

\section{REFERENCES}

ALI, M.M., ABDELGADIR, A.E., AND ISMAIL, H.M. 2014. Evaluation of Biosecurity Measure on Broiler farms in Khartoum state Sudan. Journal of Veterinary Medicine and Animal Health, vol. 6 (5), pp. 138 144, 8, 144.

AJEWPLE, O. C. AND AKINWUMI A.A. 2014. Awareness and Practice of Biosecurity measures in small scale poultry production Nigeria, journal of agricultural and veterinary science Vol. 7 issue 11 pp24-29.

BIOSECURITY PROCEDURES IN POULTRY PRODUCTION (2018). OIE Terrestrial Animal Health.

ENGLISH, K.G. 2015. Effect of Biosecurity and Management Practices on the Prevalence of Salmonella, Campylobacter, and Clostridium Perfringens in poultry Production System. MSc thesis, Auburn University

MUSTAFA, M.E. AND ISMAIL, H. M. 2017. Evaluation of Biosecurity Measures in Layer Farms in Khartoum State, Sudan. Journal of Applied Science and Research, 5 (6): 23-31.

NEGRO-CALDUCH, E. 2013. Assessment of Biosecurity Practices of Small-Scale Broiler Producers in central Egypt, Preventive Veterinary Medicine 110(2013) 253-262.

QUINTERO, DINO; et al. 2012. Workload Optimized Systems: Tuning POWER7 for Analytics.
International Business Machines Corporation. New York, United States

SCOTT AB, SINGH M, GROVES P, HERNANDEZJOVER M, BARNES B, GLASS K, et al. 2018. Biosecurity Practices on Australian commercial layer and Meat Chicken Farms: Performance and Perceptions of Farmers. Plos ONE 13(4): e0195582. https://d oi.org/10.1371/ Journal. Phone.0195582.

SINGER, 2006. Potential Impacts of Antibiotic Use in Poultry Product, Avian Diseases, 50(2):161-173.

SMITH P AND DANIEL C. 1975. The Chicken Book (Boston, M. A: Little), Brown and Company, p.258).

TABIDI, M.H., MUSTAFA, E.A. AND AHMED, 2014. Data Analysis of Biosecurity Measure for Poultry Farms Registration, November 2014, International Journal of Current Research, vol, 6, issue, 11, pp, $9714-9718,6,9718$.

YITBAREK, M. P., MERSSO, P. T., WOSEN, A. M., 2016. Disease Management and Biosecurity Measures of Small-Scale Commercial Poultry Farms in and Around Debre Markos, Amhara Region, Ethiopia, Journal of Veterinary Medicine and Animal Health, Vol. 8(10), pp. 136 - 144).

WASHBUM, K.W., 1998. Incidence, cause and prevention of egg shell breakage in Commercial production Poultry Science. 61:2005-2012.

How to cite this article:

Omer A., Salim Gibril and Abdelbasit B. Habib, 2019. Management and Biosecurity Practices on Broiler and Layer Farms in Bahri Locality Khartoum North. Journal of Applied Veterinary Sciences, 4(2): 30-34.

DOI : https://dx.doi.org/10.21608/javs.2019.62651 